\title{
A Conceptual Structure of Care Dependency in Home-Dwelling Indonesian Older Adults
}

\author{
Dara Febriana $^{1,2}$, Sang-arun Isaramalai ${ }^{1 *}$, Patcharee Komjakraphan ${ }^{1}$ \\ ${ }^{1}$ Faculty of Nursing, Prince of Songkla University, Hat Yai, Songkhla 90110, Thailand; \\ ${ }^{2}$ Faculty of Nursing, Universitas Syiah Kuala, Banda Aceh, 23111 Indonesia \\ ${ }^{*}$ Corresponding author. E-mail: isangarun@hotmail.com \\ https://doi.org/10.12982/CMUJASR.2019.0007
}

\section{ABSTRACT}

This study aims to develop a conceptual structure of care dependency for home-dwelling Indonesian older adults and to clarify the pre-specified domain that fits with the Indonesian context. The first step of the research was a review of published tools developed to assess care dependency or dependency. The instruments were reviewed to develop the pre-specified domain of care dependency in older adults, and later analysed using Orem's self-care deficit nursing theory (SCDNT). Electronic databases such as MEDLINEPubMed, CINAHL, and EMBASE were used to obtain journal articles to identify clinical studies that used the care dependency instrument. The search began by using keywords such as "care dependency", "care dependency scale" and "care dependency measurement in older adults" followed by searching through citation and reference search. The second step was to conduct a descriptive, qualitative study with 30 participants, using a semi-structured interview guide generated from the first step. The prespecified domains of care dependency were found to be organized into eight domains, namely (1)activity; (2) nutrition; (3) skin and hygiene; (4) psychosocial; (5) spiritual; (6) sleep and rest; (7) elimination; and (8) health care practices. The results of the second step showed that those eight domains were fit to the Indonesian context. In conclusion, it was found that the conceptual structure can be used to develop a scale to measure home-dwelling older adults' care dependency in future research, as well as primary care curricula to improve nursing care for the older adults who are care dependent and living at home. Moreover, it also can be used to develop programs to address problems experienced by a dependent older adults living in the community.

Keywords: Care dependency, Indonesian older adult, Conceptual structure, Orem's self-care deficit nursing theory

\section{INTRODUCTION}

Older adults represent one of the fastest-growing demographics in the world. In 2015 around 900 million people worldwide were aged 60 and older, and this number is predicted to increase to 2 billion by 2050 (WHO, 2018). In Indonesia, there are 23 million older adults $(8.97 \%)$ 
with a life expectancy of 71 years old. It is predicted that the percentage of Indonesia's elderly will reach 23 percent by 2050 (Adioetomo, Howell, McPherson, and Priebe, 2013). Indonesia is preparing to become an aging population characterized by the portion of older adult population reaching 10 percent, less than five years from now (Indonesia Bureau Statistic, 2018). A rapidly aging population raises the question of support available for sustaining their welfare, particularly when the economically active working population begins to shrink (Abikusno, 2007). Moreover, looking at living arrangements, most older adults in Indonesia live in the community, some with their family and/or other family member, and some live alone (Priebe, 2017). The increasing number of older people will raise issues associated with old age such as care dependency.

The majority of older adults experience a significant decline in overall functional capacity. This can manifest itself in chronic illness, frailty, sarcopenia, impaired gait, and being prone to falls. The consequences associated with these changes are decreased independence in mobility and daily self-care routines, hospitalization, or institutionalization into a nursing facility (Kloubec, Rozga, and Block, 2012). The old-age dependency ratio in Indonesia according to the World Bank, as cited in Index Mundi (2017) in 2016 was at 7.75\%. A higher value of dependency ratio means that employed people have to support more the non-working population. However, the dependency ratio cannot be used as the only source of data to determine the care dependency of older people. More specific measures related to care dependency are more useful in determining the level of care dependency in the older adult population.

In older adult population, dependency is considered to be the major problem due to the decline in physical and psychological status (Baltes, 1996). Dependency is a condition, which anyone can contract through illness or disability. Dependency can be a temporary, long-term, or permanent state, and care dependency is often associated with the care of older people. A review of the literature on dependency suggests that the concept is multidimensional (Gignac \& Cott, 1998). The components of dependency are often classified into broad categories that include physical, psychological, behavioural, and social dependency (George, 1991; Baltes, 1996). There are many available definitions and terminology of care dependency (Boggatz, Dijkstra, Lohrmann and Dassen, 2007), however, analysis of the care dependency in the aged especially the one perceived by Indonesian older adults has been inadequate. Additionally, the framework of care dependency for Indonesian older adults has not been clearly defined. Therefore, it is important to develop conceptual tools to be used primarily in the Indonesian context. Later these can be used as the groundwork for developing an instrument for evaluating care dependency in Indonesian older adults who live in the community. The purpose of this study was to develop a conceptual structure of care dependency for home-dwelling Indonesian older adults.

\section{METHODOLOGY}

To achieve the study objective, the first step was a review of published articles related to the measurement of care dependency to find the domain of care dependency and analyse it using Orem's Self-Care Deficit Nursing Theory (SCDNT). The second step was conducting a qualitative study to clarify and confirm the domain found from the literature. A convenient sample of 30 older adult participants was recruited into the study. According to Sandelowski (1995), 30 participants were considered to be adequate to attain the information needed without being too few to 
understand the experience; neither was it too large to undertake a deep case-oriented analysis. The inclusion criteria were: older adults age 60 years and older, able to communicate, living in the community, and willing to participate. Participants with severe mental illness and severe cognitive or language deficits as reported by their family members were excluded.

Before the data collection procedure, approval from the Ethics Committee of the Faculty of Nursing, Universitas Syiah Kuala was obtained and consent was acquired orally from all research participants.

\section{Data collection procedures}

Literature review was performed through extensive research on the following electronic databases: PubMed/MEDLINE, Cumulative Index to Nursing and Allied Health Literature (CINAHL), and EMBASE. These databases were used to find articles on instruments that measure care dependency. From well-established instruments, the concept of care dependency and its domain can be identified. The keywords used were 'care dependency', 'care dependency scale' and 'care dependency measurement in older adult'. Only English articles were selected for review.

The criteria for published articles on instrumentation was: (a) published in full-text, peerreviewed articles, published from 1980 to 2016, (b) reported the psychometric evaluation and clear operational definition, (c) included the older adult in their study, (d) assess the element of dependency or care dependency and (e) published in the English language. References from the selected studies were checked manually to identify other relevant studies that were overlooked.

The second data collection step was the use of in-depth interviews. The interview guideline form consisted of eight open-ended questions. The interview questions were generated from the study of literature. The sample questions were: what kind of activities you need to perform to maintain life, health, and well-being, and what kind of limitation that affect your ability to perform the activities?

\section{Data analysis}

First, the selected instruments were analysed from the literature. The existing tools and related concepts were synthesized using Orem's Self-Care Deficit Nursing Theory (SCDNT) as the theoretical foundation. Orem's theory was used to assess the self-care requisites and to evaluate the therapeutic self-care demands of the older adult. Determination of the older adult demands for care evolves around Orem's self-care requisites (universal self-care requisites, developmental selfcare requisites, and health deviation self-care deficit). The self-care requisites were used to determine the older adult's care demands and to identify whether the older adult can perform their action demands (Orem, 2001). From this process, the authors attempt to synthesize the finding from the empirical study with Orem's theory. The domains found in the reviewed tools were classified based on Orem's self-care requisites. The pre-specified domains of the initial structure were generated to portray the care dependency and later use to retrieve the qualitative data.

Second, the qualitative data from the interviews were analysed using content analysis. Constant comparisons between the respondent's viewpoints were performed and developed into domains portraying the care dependency in Indonesian older adults. 


\section{RESULTS}

Out of the initial screening, 53 articles were retrieved and 25 of these were selected. On further review, 19 articles were eliminated for the following reasons; (a) did not have clear information on the development of the instruments, (b) was used in children, and (c) reported the reliability and validity of the instrument elsewhere. The remaining articles $(\mathrm{N}=5)$ were analyzed for their psychometric evaluation and the domains that formulate the instrument (Table 1). From the review of five published articles on the measurement of care dependency, the pre-specified domains of care dependency were constructed and classified into two categories: physical domains and psychosocial domains.

Table 1. Conceptual frameworks and theoretical construct reported in instrument development report.

\begin{tabular}{|c|c|}
\hline Instrument name and authors & $\begin{array}{l}\text { Domains of care dependency within the } \\
\text { instrument }\end{array}$ \\
\hline $\begin{array}{l}\text { The Dutch Care Dependency } \\
\text { Scale(CDS)(1998).Developed by Ate Dijkstra. }\end{array}$ & $\begin{array}{l}\text { Physical needs } \\
\text { - Eating/drinking } \\
\text { - Incontinence } \\
\text { - Body posture } \\
\text { - Mobility } \\
\text { - Day/night pattern } \\
\text { - Getting (un)dressed } \\
\text { - Body hygiene } \\
\text { - Avoidance of danger } \\
\text { Psychosocial needs } \\
\text { - Communication* } \\
\text { - Contact with others } \\
\text { - Sense of rules/values } \\
\text { - Daily activities } \\
\text { - Recreational activities } \\
\text { - Learning ability }\end{array}$ \\
\hline $\begin{array}{l}\text { The Functional Independence Measure (FIM) } \\
\text { developed by Keith RA, Granger CV, Hamilton } \\
\text { BB, Sherwin FS in } 1987 \\
\text { Social Dependency Scale (SDS)(1980) by } \\
\text { (Benoliel, McCorkle, and Young, 1980). }\end{array}$ & $\begin{array}{l}\text { Six areas of function (self-care, sphincter control, mobility, } \\
\text { locomotion, communication and social cognition), which } \\
\text { fall under two dimensions (motor and cognitive). } \\
\text { Three capacities: everyday self-care including bathing, } \\
\text { dressing, eating and toileting; mobility including walking, } \\
\text { stair climbing, transferring and traveling; and social } \\
\text { competence which includes consciousness, role activity, } \\
\text { social interaction and social interest. }\end{array}$ \\
\hline $\begin{array}{l}\text { The Northwick Park Nursing Dependency Score } \\
\text { (NPDS) was developed by Turner-Stokes and } \\
\text { colleagues to measure nursing dependency } \\
\text { (Turner-Stokes et al., 1998) }\end{array}$ & $\begin{array}{l}\text { Basic Care Needs (BCN) section } \\
\text { (Physical Care Needs) } \\
\text { Mobility and transfers } \\
\text { 1. Mobility } \\
\text { 2. Bed transfers } \\
\text { Continence } \\
\text { 3.1 Toileting-bladder } \\
\text { 3.2 Urinary incontinence } \\
\text { 4.1 Toileting-bowels } \\
\text { 4.2 Faecal incontinence }\end{array}$ \\
\hline
\end{tabular}


Table 1. Continued.

\begin{tabular}{|c|c|}
\hline Instrument name and authors & $\begin{array}{l}\text { Domains of care dependency within the } \\
\text { instrument }\end{array}$ \\
\hline & $\begin{array}{l}\text { Washing, bathing, dressing } \\
\text { 5. Washing and grooming } \\
\text { 6. Bathing/showering } \\
\text { 7. Dressing } \\
\text { Feeding } \\
\text { 8.1 Eating } \\
\text { 8.2 Drinking } \\
\text { 8.3 Enteral feeding } \\
\text { (Cognitive/Behavioural Needs) } \\
\text { Safety, communication, behaviour } \\
\text { 9. Skin pressure relief } \\
\text { 10. Safety awareness } \\
\text { 11. Communication } \\
\text { 12. Behaviour } \\
\text { Special Nursing Needs (SNN) section* } \\
\text { A. Tracheostomy } \\
\text { B. Open wound requiring dressing } \\
\text { C. Requires >2 interventions at night } \\
\text { D. Requires psychological support } \\
\text { E. In isolation (e.g. for Methicillin-resistant Staphylococcus } \\
\text { aureus [MRSA] screening) } \\
\text { F. Acute medical/surgical intervention } \\
\text { G. Needs one-to-one 'specialing' }\end{array}$ \\
\hline $\begin{array}{l}\text { The United Kingdom Functional Independence } \\
\text { Measure and Functional Assessment Measure } \\
\text { (UK FIM and FAM) (1999) (Turner-Stokes, } \\
\text { Nyein, Turner-Stokes, and Gatenouse, 1999) }\end{array}$ & $\begin{array}{l}\text { 1) Problem solving } \\
\text { 2) Adjustment to limitations } \\
\text { 3) Emotion } \\
\text { 4) Employability } \\
\text { 5) Social interaction } \\
\text { 6) Community mobility } \\
\text { 7) Safety judgment } \\
\text { 8) Attention } \\
\text { 9) Speech intelligibility } \\
\text { 10) Comprehension }\end{array}$ \\
\hline
\end{tabular}

Note: *Excluded from further analysis because SNN section focuses only hospitalized patients.

Afterward, findings from the empirical study were synthesized using Orem's SCDNT. The domains found in the existing tools were classified based on the concept of self-care requisites. Thus, eight domains of care dependency consisting of 19 pre-specified components were identified: 1) Activity, indicated by three components, i.e. mobility, preventing fall and performing exercise and physical activities 2) Nutrition, indicated by two components, i.e., taking water/food into the body and controlling dietary practices 3)Skin and hygiene, indicated by two components, i.e. maintaining skin integrity and maintaining personal hygiene 4) Psychosocial, indicated by four components, i.e. communicating with others, controlling worry, anxiety and stress, choosing appropriate coping and maintaining social interaction 5) Spiritual, indicated by two components, i.e. connecting with God and connecting with others 6) Sleep and rest, indicated by two 
components, i.e. balancing activity and rest and sleeping 7) Elimination, indicated by two components, i.e. maintaining normal elimination pattern and maintaining sanitary condition 8) Health care practices, indicated by two components, i.e. maintaining healthy behaviour and learning about current health condition. The pre-specified domains were then used as a guide to retrieve qualitative data through interviews with the Indonesian elderly.

Table 2: Respondents characteristics ( $\mathrm{n}=30)$.

\begin{tabular}{|c|c|c|}
\hline Parameter & Frequency & Percentage (\%) \\
\hline \multicolumn{3}{|l|}{ Age groups (years) } \\
\hline $60-64$ & 10 & 33.3 \\
\hline $65-69$ & 10 & 33.3 \\
\hline $70+$ & 10 & 33.3 \\
\hline \multicolumn{3}{|l|}{ Sex } \\
\hline Female & 19 & 63.3 \\
\hline Men & 11 & 36.7 \\
\hline \multicolumn{3}{|l|}{ Marital status } \\
\hline Widowed & 18 & 60 \\
\hline Married & 12 & 40 \\
\hline \multicolumn{3}{|l|}{ Illness } \\
\hline Diabetes & 8 & 26.7 \\
\hline Hypertension & 8 & 26.7 \\
\hline Arthritis & 5 & 16.7 \\
\hline No illness & 4 & 13.3 \\
\hline Post stroke & 3 & 10.0 \\
\hline Heart disease & 2 & 6.7 \\
\hline \multicolumn{3}{|l|}{ Primary care giver } \\
\hline Children & 19 & 63.3 \\
\hline Spouse & 9 & 30.0 \\
\hline Next of kin & 2 & 6.7 \\
\hline \multicolumn{3}{|l|}{ Education } \\
\hline Did not attend school & 9 & 30.0 \\
\hline Elementary & 4 & 13.3 \\
\hline Juniorhigh school & 6 & 20.0 \\
\hline Diploma & 3 & 10.0 \\
\hline Bachelor & 8 & 26.7 \\
\hline \multicolumn{3}{|l|}{ Occupation } \\
\hline Did not work & 15 & 50.0 \\
\hline Retirement & 9 & 30.0 \\
\hline Farmer & 6 & 20.0 \\
\hline \multicolumn{3}{|l|}{ ADL's status } \\
\hline Need help & 3 & 10.0 \\
\hline $\begin{array}{l}\text { Did not need help } \\
\text { (moderate assistance ne }\end{array}$ & 27 & 90.0 \\
\hline
\end{tabular}

The characteristics of the qualitative study respondents can be found in Table 2 . The mean age of the participants $(\mathrm{n}=30)$ was 68.83 years, they were predominantly female $(63.3 \%)$ and widowed (60\%). Only $13.3 \%$ of the respondents reported that they did not have any co-morbidity or illness, diabetes and hypertension were the most prevalent illness of the respondents $(26.7 \%)$ respectively. The majority of the respondents their primary caregiver was the children $(63.3 \%)$. 
Most of them did not attend school (30\%) and did not have an occupation or paid work (50\%). For the respondent activity daily living (ADL), the interviewer asked whether they need help in performing activities such as bathing, dressing, walking, transferring, and feeding. The majority of the respondents said that they did not require any help only $10 \%$ of them did.

The findings of the interviews are signified by eight themes, which were supported by the pre-specified domain of care dependency. These were activity; nutrition; skin and hygiene; psychosocial; spiritual; sleep and rest; elimination; and health care practice. These specified domains were categorized and broken down into 18 components. The comparison between pre-specified domains, the themes from the interviews, and the specified domains can be seen in Table 3.

Table 3. Pre-specified domains, themes from interviews and specified domains of care dependency for indonesian older adult.

\begin{tabular}{|c|c|c|c|}
\hline & Pre-specified domains & $\begin{array}{l}\text { Themes from } \\
\text { qualitative study }\end{array}$ & Specified domains \\
\hline 1. & $\begin{array}{l}\text { Activity } \\
\text { 1.1 Maintaining mobility } \\
\text { 1.2 Preventing fall } \\
\text { 1.3 Exercising and physical } \\
\text { activities }\end{array}$ & 1. Activity & $\begin{array}{l}\text { 1. Activity } \\
\text { 1.1 Mobility } \\
\text { 1.2 Protecting from harm } \\
\text { 1.3 Promoting exercise and } \\
\text { physical activities }\end{array}$ \\
\hline 2. & $\begin{array}{l}\text { Nutrition } \\
\text { 2.1 Taking intakes into the } \\
\text { body } \\
\text { 2.2 Controlling dietary } \\
\text { practices }\end{array}$ & 2. Dietary practices & $\begin{array}{l}\text { 2. Nutrition } \\
\text { 2.1 Managing food intake } \\
\text { 2.2 Controlling dietary practices }\end{array}$ \\
\hline 3. & $\begin{array}{l}\text { Skin \& hygiene } \\
\text { 3.1 Maintaining skin integrity } \\
\text { 3.2 Maintaining personal } \\
\text { hygiene }\end{array}$ & 3. Sanitary practices & $\begin{array}{l}\text { 3. Skin \& hygiene } \\
\text { 3.1 Maintaining skin integrity } \\
\text { 3.2 Maintaining personal hygiene }\end{array}$ \\
\hline 4. & $\begin{array}{l}\text { Psychosocial } \\
4.1 \text { Able to communicate } \\
4.2 \text { Able to manage worry, } \\
\text { anxiety and stress } \\
\text { 4.3 Able to choose appropriate } \\
\text { coping* } \\
\text { 4.4 Maintaining social } \\
\text { interaction }\end{array}$ & 4. Psychosocial & $\begin{array}{l}\text { 4. Psychosocial } \\
\text { 4.1 Communicating well with } \\
\text { other people } \\
\text { 4.2 Managing worry and stress } \\
\text { 4.3 Maintaining social } \\
\text { interaction** }\end{array}$ \\
\hline 5 . & $\begin{array}{l}\text { Spiritual } \\
5.1 \text { Connecting with God } \\
5.2 \text { Connecting with others }\end{array}$ & 5. Spiritual & $\begin{array}{l}\text { 5. Spiritual } \\
\text { 5.1 Connecting with God } \\
\text { 5.2 Connecting with other people }\end{array}$ \\
\hline 6. & $\begin{array}{l}\text { Sleep and rest } \\
\text { 6.1 Balancing activity and rest } \\
\text { 6.2 Sleeping }\end{array}$ & 6. Energy & $\begin{array}{l}\text { 6. Sleep and rest } \\
\text { 6.1 Balancing activity and rest } \\
\text { 6.2 Managing sleep }\end{array}$ \\
\hline
\end{tabular}

Note: "Deleted component, "Merged components. 
Table 3. Continued.

\begin{tabular}{|c|c|c|c|}
\hline Pre-specified domains & $\begin{array}{l}\text { Themes from } \\
\text { qualitative study }\end{array}$ & & Specified domains \\
\hline $\begin{array}{l}\text { 7. Elimination } \\
\text { 7.1 Maintaining normal } \\
\text { elimination pattern } \\
\text { 7.2 Maintaining a sanitary } \\
\text { condition }\end{array}$ & $\begin{array}{l}\text { 7. Urination and } \\
\text { defecation }\end{array}$ & 7. & $\begin{array}{l}\text { Elimination } \\
\text { 7.1 Maintaining normal } \\
\text { elimination pattern } \\
\text { 7.2 Maintaining a sanitary } \\
\text { condition }\end{array}$ \\
\hline $\begin{array}{l}\text { 8. Health care practices } \\
\text { 8.1 Maintaining a healthy } \\
\text { behavior } \\
\text { 8.2 Learning about their } \\
\text { current health condition }\end{array}$ & 8. Maintaining health & 8. & $\begin{array}{l}\text { Health care practices } \\
\text { 8.1 Maintaining a healthy } \\
\text { behavior } \\
\text { 8.2 Getting information about } \\
\text { health-related issues }\end{array}$ \\
\hline
\end{tabular}

The details of each domain emerged and ordered from qualitative findings, as described in the following sections.

\section{Activity}

Activity was defined as the extent to which the older adult depends on others for getting help with maintaining mobility, protecting from harm, and promoting exercise and physical activities. The three components in this domain are described below.

Maintaining mobility. This refers to the extent to which the older adult depends on others to maintain their mobility. These needs are shown in the following statements.

If nearby I'll go by foot, I don't go far anymore. tired. unless my children take me there. Going too far makes me tired, sometimes there are days when I easily got tired just from walking to the Meunasah (community centre in the village where activities such as praying, discussion, and learning were held) nearby. But, even though its makes me tired sometimes, I still want to go (R9P2L3-5).

I used to go everywhere by myself. Now as I'm getting older I'm afraid to go out alone. So, whenever I'm going out my granddaughter or my son will take me, or I ask them to drive me (R10P1L2-3).

Protecting from harm. This refers to the extent to which the older adult depends on others to keep them from being harmed or injured. Included in this domain is the dependency of the older adult to be protected from falls, being injured, and help with keeping the environment safe for the older adult. "I want to make my room downstairs, so I don't have to take the stairs anymore. Because my legs getting weaker. And maybe get me a sitting toilet" (laugh) (R6P7L25-27). "Well, I try to keep the bathroom clean so I will not slip. My son often cleans it though (laugh). Luckily we don't live in a stilt house anymore so I don't have to climb stairs" (R8P5L9-10).

Promoting exercise and physical activities. This refers to the extent to which the older adult depends on others to motivate them to perform an exercise, or keeping them active. Most of the participants said that they performed exercise routinely even if only a short brisk walk in the 
morning. Some of them also said that doing the house chores is their way to 'exercise'. The participants realized the benefits of exercise to their health and well-being, and they also seek information about the type of exercise that is suitable for their age. When they feel less motivated their children often encourage them to continue their exercise by giving them motivation, or facilitating their exercise, as mentioned in the following statements.

I will stay at home and do exercise at home. Cleaning the house, going down the stairs and all the house chores can be categorized as exercise too, right? (laugh) I like to keep myself active, even though I don't have much to do at home. My daughter sometimes goes walking with me in the morning and encourages me to keep exercising. But she also said that I shouldn't work too hard at home (laugh)(R19P11-16).

"I think it would be good for me to know what kind of exercise I can do and which would benefit me with my age right now" (R18P3L4-5).

\section{Nutrition}

From the interview, nutrition was defined as the extent to which the older adult depends on others managing their food intake and controlling their dietary practices. These two components are described as follows.

Managing food intake. This refers to the extent to which the older adult depends on others to prepare the food, starting from grocery shopping, cooking, and serving the food, as well as motivating them to eat more/less and drink more.

When I'm not feeling well my daughter will do all the house chores and cooking too. I have hypertension and I shouldn't consume salt anymore. But it's difficult, you know, to eat food that has no taste. If she cooks (her daughter), I don't each much (R13P3L17-18).

Since my second stroke attack, I am practically confined to bed. I don't need to be fed, but of course, I can't go grocery shopping or cook anymore. My daughter usually prepares everything for me to eat; she always asks me what I want to eat because lately, I've been losing my appetite (R29P4L12-15).

Controlling dietary practices. This refers to the extent to which the older adult depends on others to control their food consumption. An older adult with chronic illness, especially hypertension and diabetes, tends to have a certain diet that they need to comply with. The respondents mostly said that they need to reduce the salt intake, drink less coffee, and supervised their food provision and portion.

I think I need to control my food, I need to be cautious about what kind offood I can and cannot eat. Mostly I eat fish. If they cook salty food for me I will not eat it. If they cook lado (spicy condiment) with fish I will tell them to put the fish aside, and not to mix it with the lado. I often eat kuah aneuk miet (plain soup) as well. I try to drink less coffee, but it's difficult, you know (R1P7L28-33).

I have had diabetes for years; I know what I should and should not eat. But sometimes you know, when you are with friends during a festive time and you just forget that you shouldn't 
eat "kuah beulangong" (beef gravy)..(laugh). My wife and daughters always remind me not to lose control when I go to a celebration (laugh) (R3P6L13-26).

\section{Skin and hygiene}

This refers to the extent to which the older adult depends on others to maintain skin integrity and personal hygiene. The two components of this domain are described as follows.

Maintaining skin integrity. It refers to the extent to which the older adult depends on others to keep their skin intact and to prevent cuts or any skin problems.

When I went to the paddy field I need to wear long sleeves to protect my skin from the sun and I also need to wear socks and rubber boots to protect my feet from leech bites. After I finished my work I will go home and take a shower. But I don't like to put lotion because it feels sticky (R7P3L15-18).

Maintaining personal hygiene. This refers to the extent to which the older adult depends on others to shower/bath, to wear clothes, and to motivate the older adult to brush their teeth. Interview data found that many of the older adults can bathe themselves, however, when they were sick they need help with providing them the necessary tool for them to shower such as providing the water to rinse or putting the bathing set within their reach because sometimes they have to sit when they take a shower.

Every morning I ask them to get me my toothbrush and water for me to wash my face and brush my teeth by myself. I brush my hair and change my clothes. You did all by yourself? "Yes, but I need help to put on my clothes because my arm couldn't reach inside the sleeve (R1P6L6-7).

There was this time, it happened in front of my neighbour's house. I was suddenly motionless and cannot walk anymore. My son picked me up and took me back home. When I was at home my daughter bathed me because I felt so weak and could only stay still. So she also dressed me, putting my blouse and pants and my hijab as well, I was too weak to do it (R2P2L16-22).

\section{Psychosocial}

Psychosocial was defined as the extent to which the older adult depends on others to maintain communication, to manage worry and stress, and to maintain social interaction. The three components of this domain are explained as follows.

Maintaining communication. This refers to the extent to which the older adult depends on others to maintain their communication function, to understand what they are trying to say and to understand what others are trying to say. Problems maintaining communication were experienced by older adults who had hearing problems. It usually occurs when they try to communicate with new people. Family members already understood their elder's situation and already developed a way to communicate with the older adult, while for the outsider it takes time for them to understand the older adult and vice versa.

I have difficulty in hearing. Among all of my grandchildren, she's the one who can understand me well and I can communicate with her better (referring to her granddaughter 
who sits next to her). Her voice very loud (the granddaughter), you can notice it, right (laugh). When talking to an outsider or people who do not know my condition I need her to help me (R11P3L17-20).

Managing worry and stress. This refers to the extent to which the older adult depends on others to reduce and prevent their stress and worries. When the older adult has problems they said that words of motivation and encouragement helped reduce their worries and provide comfort. Being with family and speaking about their problems also help the older adult to feel much better. The subdomain 'able to choose appropriate coping' in the pre-specified domain was merged to the subdomain 'managing worry, anxiety, and stress'. This is because, based on the interviews, the respondents did not specifically mention their method of choosing the appropriate coping systems for their problems. But, they reflected it in how they manage their worry, anxiety, and stress, and how they expect others to help them to reduce their worry, anxiety, and stress.

It never crossed my mind that I might continue to be sick forever, I believe I will be healthy again, I believe in myself... we have to be positive, right? My family often praises me for the progress that I made. They will say "its good that you can move your hand, you can move your leg". They also made me believe that someday I'll be able to walk again (R1, P5, L14-18).

Maintaining social interaction. This refers to the extent to which the older adult depends on others to maintain their social interaction with friends and relatives and their participation in the community. This can be done by going and participating in activities on the older adult's behalf, keeping in touch with the older adult's friends, having friends visit and exchanging news about the elders.

Now, there aren't so many activities that I do with my friends, but before I often went out with my friends. When my vision was still good I went for wirid (reciting Al-Quran together), went to the masjid, to my friend's house, and to the hospital to visit my friends or relatives, I like to go out. But now because of my poor vision, I limit myself to going out only when I have someone to accompany me (R2, P3, L29-33).

\section{Spiritual}

Spiritual was defined as the extent to which the older adult depends on others to connect with God and with others. These two components described as follows.

Connecting with God. This refers to the extent to which the older adult depends on others to perform shalat (pray), read the Qur'an and go to the Masjid. In Islam shalat is obligatory, it means every Muslim must perform it regardless of their physical limitation. If they cannot stand, they can sit. If they cannot sit, they can pray while lying down. Most importantly shalat should be performed by one's own. However, there are several activities before shalat that need to be done. First is cleansing by performing $w u d h u$ (ritual cleansing) and making sure the body and the clothes are free of impurities, second to ensure the place to pray is clean and the direction is correct (facing the qiblah, the direction of $\left.A l K a^{\prime} b a h\right)$. These can be done with the help of others if the older adult is unable to perform it by themselves. "I'm a 90 year old woman, Alhamdulillah (praise to Allah) I am still able to perform shalat, but sometimes when I'm too tired I ask my granddaughter to provide me water for wudhu" (R11P4L11-15). 
Connecting with others. This refers to the extent to which the older adult depends on others to maintain their silaturrahim (relation with relatives and friends). To maintain the ties with their friends and relatives, the older adults said they would visit them and meet them, or to inquire about their well-being even from far, visiting their sick relations and even participating in their funerals.

Now there aren't so many activities that I do with my friends, but before I often go out with my friends. When my vision still good I went for wirid (reciting Al-Qur'an together), to the masjid, to my friend's house, and to the hospital to visit my sick friends or relative. I like to go out. But now because of my poor vision, I have stopped going out on my own (R2P3L2933).

\section{Sleep and rest}

Sleep and rest was designed as the extent to which the older adult depends on others to balancing their activity and rest and managing their sleep. These two components described as follows.

Balancing activity and rest. This refers to the extent to which the older adult depends on others to balance their activity and rest, such as keeping the older adult active at home, splitting the housework, or arranging their resting time.

Whether I'm sick or healthy, I will always work and my daughter usually helps me with the housework too. But I don't go to the paddy field to work when I'm sick. I usually wash the dishes after salat, and after that I do my morning walk together with the other villagers, the young usually jog and I walk by myself like I always do. But when I'm too sick I will sleep, my daughter will do the cooking and all the house chores too (R7P7L11-16).

Managing sleep.This refers to the extent to which the older adult depends on others to sleep. This component needs more clarification because the pre-specified domain did not consider circumstances that can cause sleep discomfort. It is only concern whether the older adult has enough sleep or not. The majority of the respondents said they were unable to sleep well when they develop pain (mostly in the knee) and if the weather was too hot. "Generally, I do (sleep well), but when I had knee pain I usually couldn't sleep very well. I will ask my children to find my medication so I can take it to ease the pain" (R6P1L23-24).

\section{Elimination}

Eliminatin refers to the extent to which the older adult depends on others to maintain their normal elimination pattern and sanitary conditions. These two components described as follows.

Maintaining a normal elimination pattern. This refers to the extent to which the older adult depends on others to urinate and defecate. Some participants said they had a problem with passing stools due to constipation. And some of them (mostly women) had difficulty to hold the urge to urinate. "I cannot hold my urge anymore; sometime I can't even get to the toilet and often wet myself” (R9P4L4-5). 
I don't defecate every day and sometimes I have to strain during defecation, this happens depending upon what I'm eating. My daughter often gives me papaya, banana, or oranges, but sometime I couldn't finish eating them all and I always share it again with my grandchildren. I like to share food (R11P3L28-31).

Maintaining sanitary conditions. This refers to the extent to which the older adults depend on others to access the toilet and clean themselves after urinate and defecate.

I urinate quite often even though I don't drink a lot. Sometimes my daughter brought water to the house so I didn't have to take the stairs too often to go to the bathroom because the bathroom is outside the house. And I can't hold the urge for too long, I often wet myself if I have to hurry to go to the toilet (R11P3L22-25).

\section{Health care practices}

Health care practices refers to the extent to which the older adult depends on others to maintain healthy behaviour and to get information about health-related issues. These two components are described as follows.

Maintaining a healthy behaviour.This refers to the extent to which older adults depend on others to control their blood pressure, to help them with medication, and to do a regular checkup. The majority of the respondents have chronic conditions such as hypertension, diabetes, and arthritis. Therefore, health care practices usually are related to their current health status.

When I'm sick, but I can still get up and walk around the house, I don't want to go to the doctor. I just ask my children to buy the medication. But if I cannot get up anymore I will go to see the doctor or ask my children to bring the doctor home (R9P4L12-14).

Getting information about health-related issues. This refers to the extent to which the older adult depends on others to get health information, especially information about conventional medications and sometimes traditional medicines too, or to talk with the doctors. "Usually I tell the doctor about my problems and ask for medications. My daughter usually talks to the doctor and asks about my conditions" (R9P4L20-21)

To summarize, there are eight domains of care dependency specified by the older adult and the caregivers. They are activity, nutrition, skin, and hygiene, psychosocial, spiritual, sleep and rest, elimination, and health care practices.

\section{DISCUSSION}

The findings presented in this study suggest that the care dependency concept has cultural variations. Many studies on care dependency are mainly conducted in Europe and North America. However, by uncovering how care dependency is conceptualized by home-dwelling Indonesian older adults, the researcher tries to add this notion to the existing concept formed in the Western context.

The discovery of eight domains in this study is evidence that this study corresponds with previous studies' findings which stated that care dependency is multidimensional, and often has many interpretations. Furthermore, the elements of care dependency are often divided into broad 
categories (George, 1991; Baltes, 1996; Gignac \& Cott, 1998). This study managed to incorporate these broad elements of care dependency into a conceptual structure.

This study specified 8 domains and 18 components of care dependency and the result was found to be parallel with the pre-specified domain found in the literature. However, the prespecified domain has 8 domains and 19 components. Two components from the psychosocial domain have been merged into one in this study. The components are 'able to choose appropriate coping' and 'able to manage worry, anxiety, and stress'. These two components were merged because the respondent did not specifically mention coping method that they choose when they having stress or problems, however, they did mention about how they deal with their stress and worry, e.g. by talking to their children or spouse or by keeping 'things' to themselves. Therefore, these two components were merged into one because they represent the way the older adult deals with stress, anxiety, and worry.

Other components from the activity and spiritual domains were found to have slight differences with the pre-specified domain acquired from the literature. In the activity domain, the component of 'preventing fall' from the pre-specified domain was changed to "protecting from harm”. Many injuries in older adults were caused by falls (Jin, 2018). Most of the respondents do not require help with their ADLs, but some of them reported that if they fall of have an injury they afraid that it will affect their ability to perform the ADLs. However, the respondents did not focus only on falls but on many other things that can cause harm, and therefore the component "protecting from harm" was found to be more suitable.

There are distinct constructs between spirituality and religiosity that are sometimes difficult to distinguish. Spirituality may or may not lead to or arise from the development of religious rituals and the formation of the community (Koenig, King, and Carson, 2012). Respondents who participated in this study are all Muslims and according to Islamic perception spirituality defined as the existence of a relationship with God (Allah) that affects a person's self-worth, sense of meaning, and connectedness with others and nature (Nasr, 1997). Therefore, the spiritual domain and its components cannot be separated from religion and the fulfilment of spiritual needs achieved through religious activities. Most respondents in this study are able to perform religious rituals without help, especially those who did not need help with their ADL activities. However, for those who did need assistance with their ADLs only need minimal help to be able to perform religious rituals.

Based on information collected from our participants we have drawn two main conclusions. First, we found evidence that the eight specified domains confirmed through the qualitative study do have slight differences with the pre-specified one. Even though the domains were similar, some of the components somewhat different. Indonesian older adults view aspect of care dependency as a broader concept, while in the literature most aspects of care dependency is physical, with a slight notion of psychosocial aspect. Moreover, assistance required for the elderly who are care dependent based on the literature is more to the actual help or a hands-on affair, e.g., intakes into the body or ability to communicate. While the Indonesian older adults have the view that assistance can also be in the form of help with supervision, e.g. protecting from harm, helping through support and motivation, e.g. promoting exercise and physical activity. Based on this finding our second conclusion is that the difference was due to the distinctive cultural context between the existing one, which is based on Western culture and data from a qualitative study that is based on Indonesian culture. 


\section{CONCLUSION}

The finding of this study provided a better understanding of care dependency in older adults. The components of care dependency in the older adult can be used as the framework to develop a care dependency scale measuring the extent to which the older adult depends on others to perform their care demands, as reflected in the components.

\section{REFERENCES}

Abikusno, N. (2007). Older population in Indonesia: trends, issues and policy responses: UNFPA Indonesia and Country Technical Services Team for East and South-East Asia.

Adioetomo, S.M., Howell, F., McPherson, A., \& Priebe, J. (2013). Social assistance for the elderly in Indonesia: an empirical assessment of the ASLUT programme. Jakarta: Tim Nasional Percepatan Penanggulan Kemiskinan (TNP2K). Retrieved from https://archive.org/details/ working-paper-5-social assistance-for-the-elderly-in-indonesia

Baltes, M.M.(1996). The many faces of dependency in old age. New York: Cambridge University Press.

Benoliel, J., McCorkle, R., \& Young, K. (1980). Development of a social dependency scale. Research in Nursing Health, 3(1), 3-10. https://doi.org/10.1002/nur.4770030103

Boggatz, T., Dijkstra, A., Lohrmann, C., \& Dassen, T. (2007). The meaning of care dependency as shared by care giversand care recipients: a concept analysis. Journal of Advanced Nursing, 60(5), 561-569. https://doi.org/10.1111/j.1365-2648.2007.04456.x

George, S. (1991). Measures of dependency: their use in assessing the need for residential care for the older adult. Journal of Public Health Medicine, 13(3), 178-181. https://doi.org/10.1093/ oxfordjournals.pubmed.a042615

Gignac, M.A.M., \& Cott, C. (1998). A conceptual model of independence and dependence for adults with chronic physical illness and disabilit. Social Science and Medicine, 47(6), 739753. https://doi.org/10.1016/s0277-9536(98)00149-x

Index Mundi. 2017. Indonesia - Age Dependency Ratio. Retrieved February 22, 2018, from https://www.indexmundi.com/facts/indonesia/age-dependency-ratio

Indonesia Bureau Statistic. 2018. Statistik Penduduk Lanjut Usia 2018. Jakarta: Indonesia Bureau Statistic

Jin, J. (2018). Prevention of falls in older adults. JAMA, 319(16), 1734-1734. https://doi.org/ 10.1001/jama.2018.4396

Keith, R., Granger, C., Hamilton, B., \& Sherwin, F.(1987). The functional independence measure: a new tool for rehabilitation. Advance Clinic Rehabilitation, 1, 6-18.

Kloubec, J.A., Rozga, M., \& Block, M. (2012). Balance improvements in independent-living older adult adults following a 12-week structured exercise program. Activities, Adaptation \& Aging, 36(2), 167-178. https://doi.org/10.1080/01924788.2012.673158

Koenig, H., King, D., \& Carson, V.B. (2012). Handbook of religion and health. UK: Oxford University Press.

Nasr, S.H. (1997). Islamic spirituality: Foundations. New York: Crossroad Publishing Company.

Orem, D.E. (2001). Nursing: Concepts and Practice (6 ${ }^{\text {th }}$ ed.). St. Louis: MO, Mosby 
Priebe, J. (2017). Old-age poverty in Indonesia: Measurement issues and living arrangements. Development and Change, 48(6), 1362-1385. https://doi.org/10.1111/dech.12340

Sandelowski, M. (1995). Sample size in qualitative research. Research in Nursing \& Health, 18(2), 179-183. https://doi.org/10.1002/nur.4770180211

Turner-Stokes, L., Nyein, K., Turner-Stokes, T., \& Gatehouse, C. (1999). The UK FIM+FAM: development and evaluation. Clinical Rehabilitation, 13(4), 277-287. https://doi.org/10. $1191 / 026921599676896799$

Turner-Stokes, L., Tonge, P., Nyein, K., Hunter, M., Nielson, S., \& Robinson, I. (1998). The Northwick Park Dependency Score (NPDS): a measure of nursing dependency in rehabilitation. Clinical Rehabilitation, 12(4), 304-318. https://doi.org/10.1191/0269215 98669173600

World Health Organization. (2018). The global network for age-friendly cities and communitites: looking back over the last decade, looking forward to the next. Geneva, Switzerland: World Health Organization. Retrived from https:/www.who.int/ageing/publications/gnafccreport-2018/en/ 